\title{
Terminology and Source Notes
}

To ensure the anonymity of those interviewed (see Appendix, List of Interviews), I have been purposely vague where possible. Thus I use the general abbreviation " $\mathrm{AB}$ " for administration board without naming the specific position (e.g., AB: Central Transvaal). The abbreviation " $\mathrm{DL}$ " refers to the director of labor of an administration board (e.g., DL: Northern Transvaal), though frequently I interviewed the deputy or assistant. "LB" denotes an interview with the director of a labor bureau (e.g., LB: Hammanskraal). I have not given the dates of interviews, so that the natural rotation in the bureaucracy, common at the labor bureau level, will cover my tracks. Where the speaker is indicated by the text itself (e.g., "the legislative advisor observes that ...."), further citation of the source in parentheses or a note is obviously redundant and has been omitted.

The various permutations of the old Department of Native Affairs, now the Department of Constitutional Development and Planning, are often referred to in the text and notes simply as "the department." The name changes and dates are as follows:

Department of Native Affairs I9II-57

Department of Bantu Administration and Development $\quad$ I958-77

Department of Plural Relations and Development $\quad 1978$

Department of Cooperation and Development $\quad$ 1978-84

Department of Constitutional Development and Planning 1985- 
